\title{
Targeted therapies in cancer: where are we going?
}

\author{
Elisa Giovannetti ${ }^{1,2}$, Jose A. Rodriguez ${ }^{3}$ \\ 'Department Medical Oncology, Lab Medical Oncology, VU University Medical Center, Cancer Center Amsterdam, Amsterdam \\ $1081 \mathrm{HV}$, The Netherlands. \\ ${ }^{2}$ Cancer Pharmacology Lab, AIRC Start Up Unit, University of Pisa, Pisa 56100, Italy. \\ ${ }^{3}$ Department of Genetics, Physical Anthropology and Animal Physiology, University of the Basque Country, Barrio Sarriena s/n, \\ Leioa 48940, Spain.
}

Correspondence to: Dr. Elisa Giovannetti, Department Medical Oncology, Lab Medical Oncology, VU University Medical Center, Cancer Center Amsterdam, De Boelelaan 1117, Amsterdam 1081HV, The Netherlands, E-mail: elisa.giovannetti@gmail.com

How to cite this article: Giovannetti E, Rodriguez JA. Targeted therapies in cancer: where are we going? Cancer Drug Resist 2018;1:82-6. http://dx.doi.org/10.20517/cdr.2018.05

Received: 4 May 2018 Accepted: 7 May 2018 Published: 19 Jun 2018

Science Editor: Godefridus J. Peters Copy Editor: Jun-Yao Li Production Editor: Cai-Hong Wang

\section{SPECIAL ISSUE INTRODUCTION}

Targeted therapies in cancer aim to specifically block the activity of crucial proteins or signaling pathways necessary for the growth and/or survival of tumor cells. A major breakthrough in targeted cancer therapy was the introduction nearly two decades ago of imatinib, an inhibitor of the BCR-ABL tyrosine kinase for the treatment of chronic myeloid leukemia. Over the last years, significant advances in our understanding of tumor biology have facilitated the development of many drugs targeting not only kinases, but also other protein families and cellular processes. Several of these agents are currently employed or being implemented for the treatment of different hematologic and solid malignancies, such as lung cancer. The special issue on "Targeted cancer therapy" will include reviews and commentaries updating the clinical use of targeted agents in the treatment of different tumor types, and the mechanisms that underlie the action of drugs directed to different types of targets. The special issue will also include research articles presenting novel outstanding data on all aspects of targeted cancer therapy. All submissions will undergo rigorous peer review and will be published free of charge upon acceptance.

\section{PRELIMINARY EDITORIAL}

This special issue will provide a comprehensive overview of novel effective anticancer-targeted compounds to readers working in basic biomedical sciences as well as clinicians. It will cover drugs targeting not only kinases, but also other protein families and cellular processes, with the aim of clarifying their development, pharmacology, resistance factors, and new strategies and applications, against major tumors.

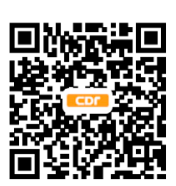


During the past two decades novel anticancer treatments have emerged from advances in our understanding of tumor cell biology, and a number of molecular and biologic targets have been identified. New drugs have been developed to attack these targets and their use to neutralize specific molecules or genes involved in the development of cancer is appropriately called "targeted therapy". The development of these novel molecularly targeted agents responds to the fact that conventional chemotherapeutic treatments have reached an efficacy plateau against most solid tumors, and deal with significant toxicity ${ }^{[1]}$. Cytotoxic drugs inflict cell death by affecting processes that are commonly overactive or enhanced in tumor compared with normal cells, such as DNA synthesis. Biologic agents interact with receptors, ligands, signaling molecules, or genes that are pivotal in tumor growth and development, and they can inhibit tumor cell proliferation, induce programmed cell death, inhibit angiogenesis, or enhance antitumor immune response $\mathrm{e}^{[2,3]}$.

A number of targeted therapies are currently employed or being implemented for the treatment of different hematologic and solid malignancies, such as imatinib, an inhibitor of the BCR-ABL tyrosine kinase for the treatment of chronic myeloid leukemia ${ }^{[4]}$, and the first-, second- and third-generation EGFR inhibitors gefitinib, erlotinib, afatinib and osimetinib in non-small cell lung cancer (NSCLC) ${ }^{[5]}$. Others are currently being evaluated as both monotherapy and in combination with cytotoxic drugs or others targeted agents.

However, several clinical studies demonstrated that targeted therapy in combination with cytoreductive chemotherapy should not be given to all patients irrespective of their characteristics, but only to individuals presenting the molecular target of the therapy and in whom these targets are crucial for cancer cell survival ${ }^{[6]}$.

Crizotinib clearly represents an example of a successful application of such straightforward development from chemical identification of the active principle to the demonstration of its clinical activity and approval for clinical use. From the very early stages during its development it was indeed evident that it would target both c-Met and the EML4-ALK gene fusion product described in 5\%-10\% of NSCLC patients ${ }^{[7]}$. This produced accelerated clinical development in those patients and it took only three years to complete a phase III trial in selected patients, achieving excellent results, and to obtain FDA registration.

A proper pharmacological evaluation should also be accompanied by a deeper understanding of the genetic heterogeneity of most tumors, as detected using patient samples obtained during treatment and following disease progression ${ }^{[8]}$. Only then, these innovative therapeutic approaches are expected to improve the efficacy and selectivity of current anticancer regimens.

Since the vast majority of advances in the treatment of cancer have resulted from the use of combination therapy, another important issue is the correct development of combination of newer agents with chemotherapy. Drug combinations are indeed widely used because multiple drugs affect multiple targets and cell subpopulations, increasing the therapeutic effect and minimizing drug resistance, but in several cases the addition of new targeted agents to standard regimens failed to improve survival ${ }^{[9,10]}$.

This outcome may be explained by the lack of patient selection as well as by other factors, including possible negative interaction or suboptimal design of the studies, inaccurate evaluation of antitumor efficacy, and controversies on drug combination analysis in preclinical models. Of note, only a few preclinical studies predicted such disappointing outcomes ${ }^{[1]}$, and further studies on potential molecular mechanisms underlying the interaction between chemotherapy and are needed (as illustrated in the Figure 1 for the preclinical data on combination of anti-EGFR agents and chemotherapeutic compunds). Cytotoxic agents and EGFR inhibitors may interact through modulation of the main downstream signalling pathways regulated by EGFR. The phosphorylation of EGFR occurs in response to several cytotoxic stresses including various anticancer drugs (i.e. in a SRC-dependent manner after cisplatin) and correlates with the synergistic inhibition of cell growth and induction of apoptosis by anti-EGFR agents ${ }^{[12]}$. EGFR phosphorylation also 


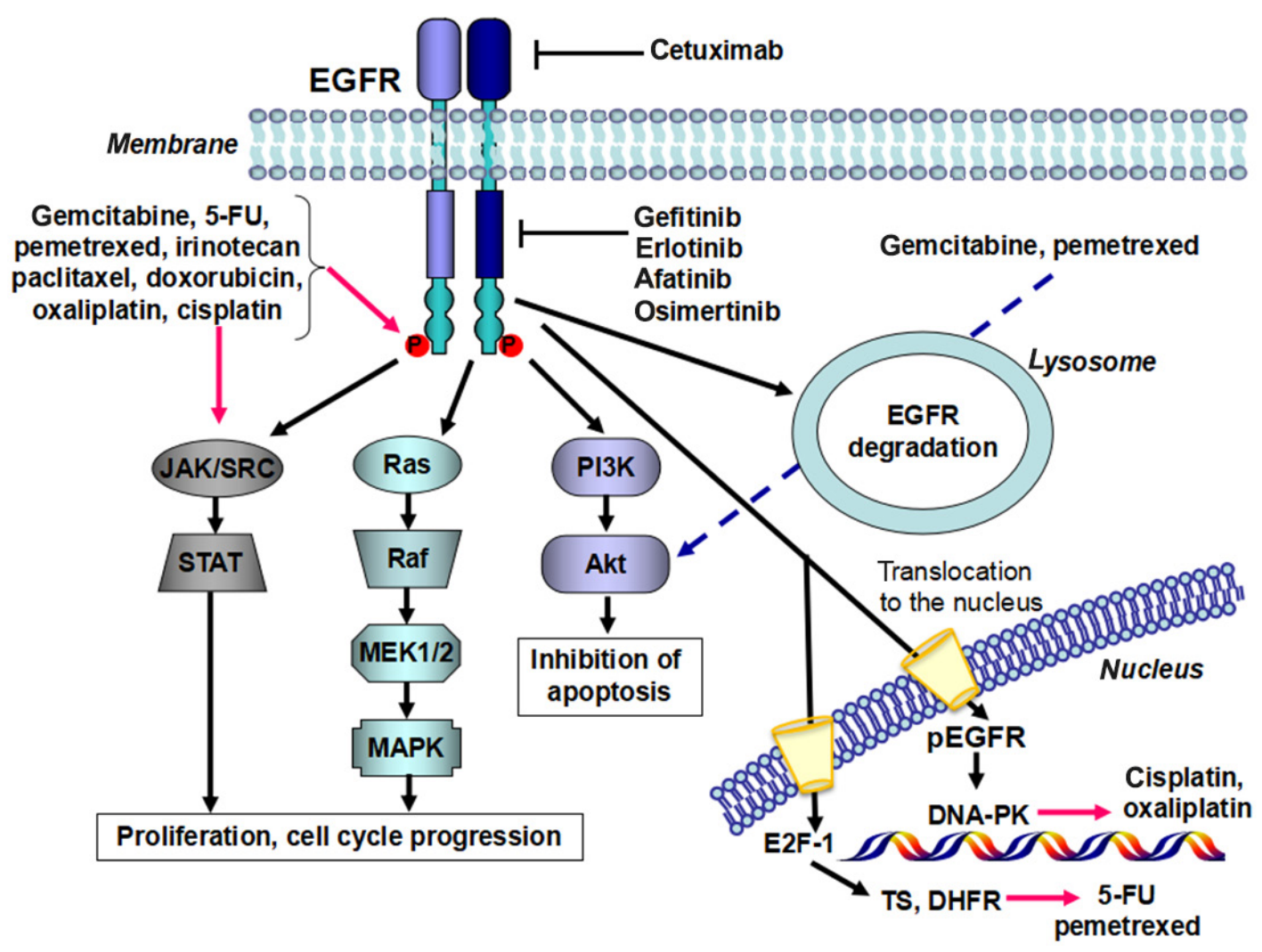

Figure 1. Interaction between chemotherapy and anti-EGFR agents: data from preclinical studies

activates Akt, but the subsequent ubiquitylation of the receptor leads to its degradation along a proteosome or lysosome pathway, resulting in phospho-Akt downregulation, as shown with gemcitabine and pemetrexed. The reduced phospho-EGFR nuclear transport reduced the expression of E2F-1, TS and dihydrofolate reductase, thus favouring 5 -fluorouracil (5-FU) and pemetrexed activity ${ }^{[13-15]}$. Finally, EGFR inhibitors might reduce DNA-dependent protein kinases (DNA-PK) expression and the repair of DNA inter-strand crosslinks and platinum adducts ${ }^{[16,17]}$.

Regarding this issue, cancer is a multifaceted disease and preclinical models used to characterize the molecular context in which synergistic interaction may occur should be implemented with appropriate design and simple, but mathematically robust methods. Several attempts have been made to quantitatively measure the dose-effect relationship of each drug alone and its combinations and to determine whether a given combination would gain a synergistic effect. In a review by Greco et al. ${ }^{[18]}$, thirteen different methods for determining synergism were listed and none of them supported the others. In a following extensive review, $\mathrm{Chou}^{[19]}$ suggested the extension of mass-action law to multiple drug-effect systems and illustrated the theoretical basis to optimize the experimental design for drug combination studies. However, tissue specific features such as pharmacokinetics and toxicity cannot be studied in vitro. Nonetheless, cells in culture retain many features of inherent intracellular biochemistry and metabolism, and environmental as well as experimental conditions can be controlled easily and precisely. Provided the researcher is aware of their limitations, then cell cultures may be a useful experimental tool and cautious extrapolation to the clinic might be possible, particularly when the cell data are entirely consistent with in vivo results.

Therefore, the articles of this special issue will highlight aspects that are of outmost importance for effective targeted agent combinations as well as to overcome molecular mechanisms conferring resistance. Other studies will discuss the identification of new biomarkers that would help in the selection of the optimal drug 
and schedule as well as the development of new technologies to decipher drug sensitivity and/or resistance which might be applied to the patient before and during treatment, using samples from surrogate tissues, including liquid biopsies.

\section{DECLARATIONS}

\section{Authors' contributions}

Manuscript writing: Giovannetti E

Manuscript revision: Rodriguez JA

\section{Financial support and sponsorship}

None.

\section{Conflicts of interest}

There are no conflicts of interest.

\section{Patient consent}

Not applicable.

\section{Ethics approval}

Not applicable.

\section{Copyright}

(c) The Author(s) 2018.

\section{REFERENCES}

1. Gutierrez ME, Kummar S, Giaccone G. Next generation oncology drug development: opportunities and challenges. Nat Rev Clin Oncol 2009;6:259-65.

2. Park SR, Davis M, Doroshow JH, Kummar S. Safety and feasibility of targeted agent combinations in solid tumours. Nat Rev Clin Oncol 2013;10:154-68.

3. Rolfo C, Caglevic C, Santarpia M, Araujo A, Giovannetti E, Gallardo CD, Pauwels P, Mahave M. Immunotherapy in NSCLC: a promising and revolutionary weapon. Adv Exp Med Biol 2017;995:97-125.

4. Hochhaus A, Larson RA, Guilhot F, Radich JP, Branford S, Hughes TP, Baccarani M, Deininger MW, Cervantes F, Fujihara S, Ortmann CE, Menssen HD, Kantarjian H, O'Brien SG, Druker BJ; IRIS Investigators. Long-term outcomes of imatinib treatment for chronic myeloid leukemia. N Engl J Med 2017;376:917-27.

5. Van Der Steen N, Deben C, Deschoolmeester V, Wouters A, Lardon F, Rolfo C, Germonpré P, Giovannetti E, Peters GJ, Pauwels P. Better to be alone than in bad company: the antagonistic effect of cisplatin and crizotinib combination therapy in non-small cell lung cancer. World J Clin Oncol 2016;7:425-32.

6. Codacci-Pisanelli G, Frati L, Mini E. Three cheers for targeted therapy in non-small cell lung cancer... When we hit the target! J Chemother 2011;23:245-6.

7. Kwak EL, Bang YJ, Camidge DR, Shaw AT, Solomon B, Maki RG, Ou SH, Dezube BJ, Jänne PA, Costa DB, Varella-Garcia M, Kim WH, Lynch TJ, Fidias P, Stubbs H, Engelman JA, Sequist LV, Tan W, Gandhi L, Mino-Kenudson M, Wei GC, Shreeve SM, Ratain MJ, Settleman J, Christensen JG, Haber DA, Wilner K, Salgia R, Shapiro GI, Clark JW, Iafrate AJ. Anaplastic lymphoma kinase inhibition in non-small-cell lung cancer. N Engl J Med 2010;363:1693-703.

8. Amirouchene-Angelozzi N, Swanton C, Bardelli A. Tumor evolution as a therapeutic target. Cancer Discov 2017; doi: 10.1158/21598290.CD-17-0343.

9. Herbst RS, Giaccone G, Schiller JH, Natale RB, Miller V, Manegold C, Scagliotti G, Rosell R, Oliff I, Reeves JA, Wolf MK, Krebs AD, Averbuch SD, Ochs JS, Grous J, Fandi A, Johnson DH. Gefitinib in combination with paclitaxel and carboplatin in advanced non-smallcell lung cancer: a phase III trial--INTACT 2. J Clin Oncol 2004;22:785-94.

10. Giaccone G, Herbst RS, Manegold C, Scagliotti G, Rosell R, Miller V, Natale RB, Schiller JH, Von Pawel J, Pluzanska A, Gatzemeier U, Grous J, Ochs JS, Averbuch SD, Wolf MK, Rennie P, Fandi A, Johnson DH. Gefitinib in combination with gemcitabine and cisplatin in advanced non-small-cell lung cancer: a phase III trial--INTACT 1. J Clin Oncol 2004;22:777-84.

11. Van Der Steen N, Caparello C, Rolfo C, Pauwels P, Peters GJ, Giovannetti E.New developments in the management of non-small-cell lung cancer, focus on rociletinib: what went wrong? Onco Targets Ther 2016;9:6065-74. 
12. Knight LA, Di Nicolantonio F, Whitehouse P, Mercer S, Sharma S, Glaysher S, Johnson P, Cree IA. The in vitro effect of gefitinib ('Iressa') alone and in combination with cytotoxic chemotherapy on human solid tumours. BMC Cancer 2004;4:83.

13. Van Schaeybroeck S, Karaiskou-McCaul A, Kelly D, Longley D, Galligan L, Van Cutsem E, Johnston P. Epidermal growth factor receptor activity determines response of colorectal cancer cells to gefitinib alone and in combination with chemotherapy. Clin Cancer Res 2005;11:7480-9.

14. Bianco C, Giovannetti E, Ciardiello F, Mey V, Nannizzi S, Tortora G, Troiani T, Pasqualetti F, Eckhardt G, de Liguoro M, Ricciardi S, Del Tacca M, Raben D, Cionini L, Danesi R. Synergistic antitumor activity of ZD6474, an inhibitor of vascular endothelial growth factor receptor and epidermal growth factor receptor signaling, with gemcitabine and ionizing radiation against pancreatic cancer. Clin Cancer Res 2006;12:7099-107.

15. Li T, Ling YH, Goldman ID, Perez-Soler R. Schedule-dependent cytotoxic synergism of pemetrexed and erlotinib in human non-small cell lung cancer cells. Clin Cancer Res 2007;13:3413-22.

16. Xu JM, Azzariti A, Severino M, Lu B, Colucci G, Paradiso A. Characterization of sequence-dependent synergy between ZD1839 ("Iressa") and oxaliplatin. Biochem Pharmacol 2003;66:551-63.

17. Magné N, Fischel JL, Tiffon C, Formento P, Dubreuil A, Renée N, Formento JL, Francoual M, Ciccolini J, Etienne MC, Milano G. Molecular mechanisms underlying the interaction between ZD1839 ('Iressa') and cisplatin/5-fluorouracil. Br J Cancer 2003;89:585-92.

18. Greco WR, Bravo G, Parsons JC. The search for synergy: a critical review from a response surface perspective. Pharmacol Rev $1995 ; 47: 331-85$.

19. Chou TC. Theoretical basis, experimental design, and computerized simulation of synergism and antagonism in drug combination studies. Pharmacol Rev 2006;58:621-81. 